\title{
A global analysis of heat-related labour productivity losses under climate change-implications for Germany's foreign trade
}

\author{
Nina Knittel ${ }^{1} \mathbb{D} \cdot$ Martin W. Jury $^{1} \cdot$ Birgit Bednar-Friedl $^{1,2} \cdot$ Gabriel Bachner $^{1} \cdot$ \\ Andrea K. Steiner ${ }^{1,3}$
}

Received: 25 September 2018 / Accepted: 16 January 2020 / Published online: 3 February 2020

(C) The Author(s) 2020

\begin{abstract}
We investigate climate change impacts transferred via foreign trade to Germany, a country that is heavily engaged in international trade. Specifically, we look at temperature changes and the associated labour productivity losses at a global scale until 2050. We assess the effects on Germany's imports and exports by means of a global computable general equilibrium (CGE) model. To address uncertainty, we account for three Shared Socioeconomic Pathways (SSP1, SSP2 and SSP3) and two Representative Concentration Pathways (RCP4.5 and RCP8.5) using projections from five global climate models. We find that average annual labour productivity for high intensity work declines by up to $31 \%$ for RCP4.5 (and up to 38\% for RCP8.5) in Southeast Asia and the Middle East by 2050, all relative to a 2050 baseline without climate change. As a consequence, for RCP8.5, Germany's imports from regions outside Europe are lower by up to $2.46 \%$, while imports from within Europe partly compensate this reduction. Also, Germany's exports to regions outside Europe are lower, but total exports increase by up to $0.16 \%$ due to higher exports to EU regions. Germany's GDP and welfare, however, are negatively affected with a loss of up to $-0.41 \%$ and $-0.46 \%$, respectively. The results highlight that overall positive trade effects for Germany constitute a comparative improvement rather than an absolute gain with climate change.
\end{abstract}

Keywords Heat stress $\cdot$ Climate change $\cdot$ Labour productivity shocks $\cdot$ International trade Computable general equilibrium $\cdot$ Germany

Electronic supplementary material The online version of this article (https://doi.org/10.1007/s10584-02002661-1) contains supplementary material, which is available to authorized users.

Nina Knittel

nina.knittel@uni-graz.at

Extended author information available on the last page of the article 


\section{Introduction}

Climate change impact assessments to date largely neglect impacts occurring beyond the borders of the region at focus. Despite a strong global economic integration, there is a vast literature focussing only on climate change impacts that occur within Europe or specific European countries (Aaheim et al. 2012; Ciscar et al. 2011, 2014; Eskeland and Mideksa 2010; Golombek et al. 2012; Roudier et al. 2016; Wachsmuth et al. 2013). However, the European Environment Agency (2017) emphasises that there is strong evidence for European countries being sensitive to climate change impacts occurring beyond European borders, as demonstrated by economic effects of weather-related global price volatilities or impacts on transportation networks such as ports. While several reports have indicated this risk, such as the UK Climate Change Risk Assessment (Challinor et al. 2016), research papers so far have mostly ignored this transmission of climate change impacts via international trade (Hewitson et al. 2014; Oppenheimer et al. 2014; Liverman 2016; Benzie et al. 2016). Hence, by only including the direct (i.e. within region) impact on countries or focus regions, the true magnitude of economic consequences of climate change might be substantially underestimated. We thus argue that it is crucial to also include the impacts in non-European countries and their transnational effects on Europe through foreign trade channels.

The research field on transnational impacts of climate change is just evolving; however, some studies have addressed the transnational dimension of climate change in one way or the other. On a national level, qualitative studies have been conducted for Finland (Kankaanpää and Carter 2007), Switzerland (INFRAS et al. 2007), the Netherlands (Vonk et al. 2015), and the UK (UK Foresight 2011; PricewaterhouseCoopers (2013); Challinor et al. 2016); there are also some studies available with a particular focus on coastal areas (Nicholls and Kebede 2012). Complementary to these qualitative studies, indicator-based vulnerability assessments have addressed this issue, such as the transnational climate impacts index (TCI), which accounts for the trade openness of a country (Benzie et al. 2016; Hedlund et al. 2018), or the "Klimacheck" tool by Lühr et al. (2014).

With a focus on the full supply chain, several studies apply multi-regional input-output (MRIO) or network analyses. Wenz and Levermann (2016), for example, provide an assessment of heat stress-related losses in a global supply network model which builds on MRIO data. They find that the intensification of trade over the period 1991-2011 increased the international propagation of production losses stronger than climatic changes over this decade. West et al. (2015) use an input-output model and climatically driven crop yield change projections to assess future crop supply for the UK. Within a regionalised, climate-sensitive, dynamic computable general equilibrium (CGE) model, Schenker (2013) studies the international spill-over of climate impacts globally, showing that climate change affects terms of trade and sectoral competitiveness. More recently, Willner et al. (2018) showed for fluvial floods that indirect losses through trade connections can exceed direct losses by multiple times. However, despite these recent attempts to quantify the propagation of climate change impacts via international trade, the academic literature still lacks assessments for future time periods. The present paper fills this research gap by investigating different climate scenarios until 2050.

Taking Germany as an illustrative case, we answer the question to which extent climate change impacts outside of the focus region (i.e. Germany) affect the local economy through foreign trade channels. Germany serves as a good example as it is the largest European economy (in terms of GDP) and is heavily engaged in international trade with a foreign trade-to-GDP ratio of $89 \%$ in 2018 (Destatis 2019). Regarding the type of climate change 
impact, we choose heat-induced labour productivity losses as an example, which has been shown to be among the most severe global impacts (Dellink et al. 2017; Kjellstrom and McMichael 2013; Roson and Van der Mensbrugghe 2012). Also, it has been demonstrated that labour productivity losses have stronger impacts in regions that are already hot today than in cooler regions (Kjellstrom et al. 2009a, b; Kjellstrom 2016), thus being strongly imbalanced across regions in its direct effects. DARA and Climate Vulnerable Forum (2012) show that labour productivity losses due to workplace heat in 2030 in low and high greenhouse gas emitting developing countries is higher by a factor of 21 and 28, respectively, as compared with developed countries.

While there exists a broad literature on health impact assessments of climate change in physical terms and the direct heat-related reductions in work ability, ${ }^{1}$ only few studies assess the (macro)economic consequences thereof (Watkiss and Hunt 2012). For instance, Kjellstrom et al. (2009b) find that by the 2080s, the greatest absolute losses of population-based labour work capacity are in the range of 11 to $27 \%$ in Southeast Asia, Andean and Central America, and the Caribbean. Dunne et al. (2013) find that work ability will reduce to $80 \%$ in peak months by 2050. Some studies estimate the domestic macroeconomic costs arising through the reduction in work ability, still ignoring international spill-over effects (DARA and Climate Vulnerable Forum 2012; Steininger et al. 2015). The most comprehensive study in this field is provided by Takakura et al. (2017), who assess the costs of heat-related illness prevention for 17 regions and at the global level for different climate and socioeconomic scenarios by the end of the century and find that global average GDP losses range between 0.5 and $4 \%$.

To summarise, the existing literature has demonstrated the importance of heat-related productivity losses, and how climate change intensifies this problem, particularly in regions which are exposed to substantial heat-related productivity losses already today. Some regions are hardly affected today, and their risk from direct impacts is expected to increase only slightly in the future. However, due to international trade, economies are intensely connected, and effects occurring in trading partner countries may spill-over to countries that are domestically less affected, such as Germany. As there are hardly any studies on the macroeconomic consequences of these spill-over effects, we contribute to and complement the impact assessment literature by investigating the transnational effects of climate change.

We assess the effects by means of a global, multi-regional, multi-sectoral CGE model comparing a baseline scenario with a climate change scenario in 2050. To address uncertainty, we run our simulation under three Shared Socioeconomic Pathways (SSP1, SSP2 and SSP3) combined with two Representative Concentration Pathways (RCP4.5 and RCP8.5), using projections from five global climate models.

The remainder of the paper is structured as follows. In section 2, we describe how labour productivity losses are calculated. In section 3, we present the CGE model that is used to assess the heat-related productivity losses that are transferred to Germany via international trade, including a description of the scenario framework as well as the model implementation of productivity losses. In section 4, we present results on Germany's macroeconomic indicators (GDP, welfare) and changes in trade patterns. In section 5, we summarise and discuss key insights.

\footnotetext{
${ }^{1}$ In the health literature, the concept of work ability entails the physical circumstances of a human body and its reactions to changes in the environment, such as temperature. Once this concept is transferred to economic assessments, we use the term labour productivity as this is more appropriate when applied to the inputs in production.
} 


\section{Climate change impact on labour productivity}

Occupational health professionals and physicians suggest that higher temperature and humidity have substantial influence on occupational health and the productivity of workers (Kjellstrom et al. 2009a). With higher temperature and rising humidity triggered by climate change, workers are not only more susceptible to illnesses but also more prone to errors and accidents due to declining concentration leading to productivity decreases (Parsons 2014). Heat extremes involve additional health risks such as heat strokes, strong dehydration or exhaustion with body core temperatures above $40.6^{\circ} \mathrm{C}$ being life-threatening (NIOSH 1986; Smith et al. 2014; Kjellstrom et al. 2016). A worker's thermal comfort as well as his/her physical and physiological limits determines the work ability and has therefore a direct influence on the productivity of businesses or the total economy (Kjellstrom et al. 2009b).

The so-called Wet Bulb Globe Temperature (WBGT) index combines temperature, humidity, wind speed and heat radiation into one value (Kjellstrom 2016) and provides the computational basis for calculating work ability in the context of climate change (Burke et al. 2015; DARA and Climate Vulnerable Forum 2012; Roson and Sartori 2016; Roson and Van der Mensbrugghe 2012; Takakura et al. 2017; Zander et al. 2015). We use daily data from five bias-corrected general circulation model (GCM) projections provided by the Inter-Sectoral Impact Model Intercomparison Project (ISIMIP, Hempel et al. 2013; Warszawski et al. 2014). These five GCMs (MIROCESM-CHEM, IPSL-CM5A-LR, GFDL-ESM2M, HadGEM2-ES and NorESM1-M) participated in the Coupled Model Intercomparison Project phase 5 (CMIP5, Taylor et al. 2012). Projections are available for the representative concentration pathways' (RCPs) emission trajectories accounting for various current and future human behaviours in terms of greenhouse gas emissions (Moss et al. 2010). In particular, we draw on data from the historical, RCP4.5, and RCP8.5 experiments for our base period (1981-2010) and the future period (2036-2065).

Several approaches to calculate WBGT exist, varying in the number of required atmospheric input variables (Liljegren et al. 2008; Dunne et al. 2013; Takakura et al. 2017; Grundstein and Cooper 2018). In this paper, we focus on daily mean work ability changes on a global scale based on GCM data with $0.5^{\circ} \times 0.5^{\circ}$ resolution. We estimate future WBGT values following the approach of Kjellstrom et al. (2009b). In the first step, daily 2-m air temperature and nearsurface relative humidity data from the ISIMIP-GCMs is used to estimate daily WBGT values for each grid cell. Subsequently, we calculate work ability changes based on Bröde et al. (2017) for two different work environments (indoor and outdoor) utilising a functional relationship between WBGT and three work intensities: light work such as office work, medium work and heavy physical work such as construction work. Finally, we aggregate both present and future work ability levels from grid cell to the model regions used in the CGE model, taking account of different population development pathways for each of the shared socioeconomic pathways (SSP1, SSP2 and SSP3). As the effect of current work ability levels is implicitly included in current indices of economic production, we calculate the relative changes with respect to the base period (1981-2010). The change in work ability accounts for current levels of acclimatisation in the different climatic zones and existing physiological limits. It does not capture effects of longerterm heat exposure that could eventually induce additional acclimatisation. ${ }^{2}$ Moreover, as is a typical assumption employed in impact assessments, the exposure-response relationship for indoor work is applied under the assumption of no additional air conditioning. A detailed description of the calculations is available in the Supplementary Material (SM, section 1).

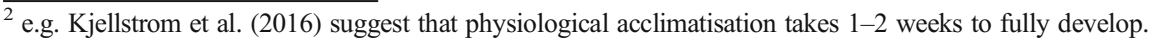


Figure 1 shows mean GCM projections of the annual WGBT cycle and corresponding work ability and relative changes for heavy outdoor work for four selected locations of the world. In general, projections of climate change show a rise in WBGT (solid lines), which leads to a decline in work ability (WA, dashed lines), also indicated by the relative changes ( $\triangle \mathrm{WA}$, dotted lines). The exposure-response relationship between WBGT and work ability is not linear (see SM, section 1). Increases in already high WBGT values lead to stronger declines in work ability (cf. Fig. b showing the annual cycle for Shanghai) as compared with increases in low WBGT values which may have no effect at all. Accordingly, cooler locations like Berlin (Fig. 1a) are projected to experience lower declines in work ability than already warm locations (e.g. equatorial regions) such as Mumbai (Fig. 1d). Figure 1 shows work ability and relative changes for heavy outdoor work; however, similar but less pronounced findings hold also for indoor work and other work intensities.

\section{Methodology}

\subsection{Economic model overview: computable general equilibrium model}

To assess the effects of a changing work ability on Germany's trade flows, we deploy a global, multi-regional, multi-sectoral CGE model. The model is based on Bednar-Friedl et al. (2012) and has been updated to the latest available GTAP database (Global Trade

(a) Berlin

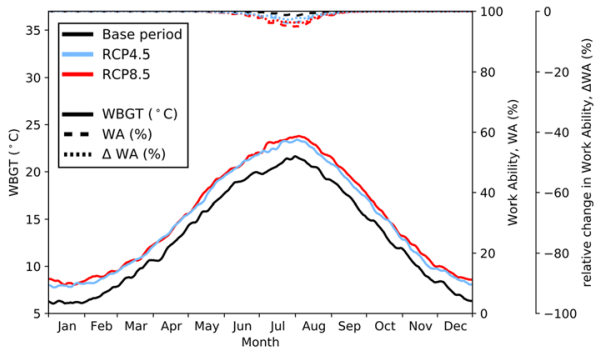

(c) Rio de Janeiro

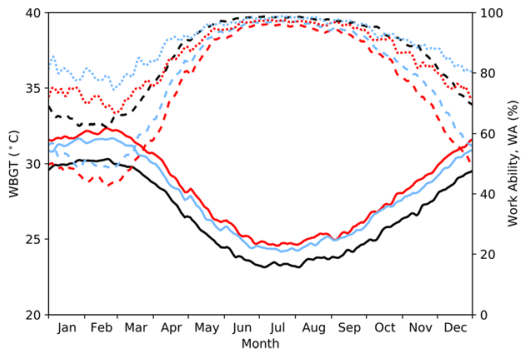

(b) Shanghai

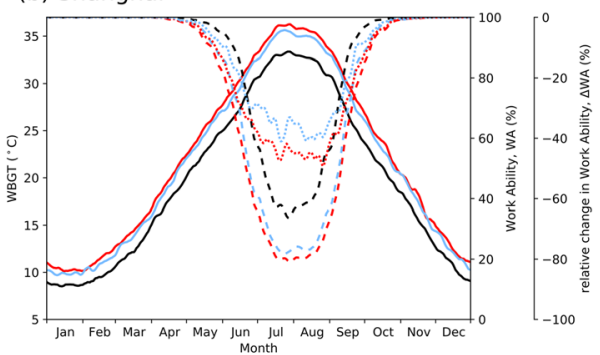

(d) Mumbai

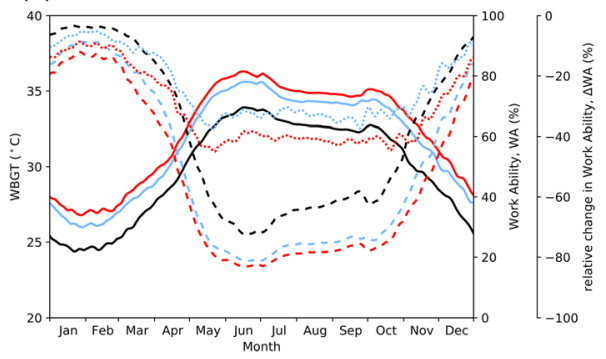

Fig. 1 Annual cycle of WBGT (solid lines, in ${ }^{\circ} \mathrm{C}$ ) and corresponding heavy outdoor work ability (dashed lines, in \%) and the relative change signal thereof (dotted lines, in \%) for a Berlin, b Shanghai, c Rio de Janeiro and $\mathbf{d}$ Mumbai. Values of the base period (Ø1981-2010) are shown in black, projections for mid of the century (Ø2036-2065) in colour blue: RCP4.5 and red: RCP8.5. Values are 5-day running means for the mean of all five GCM projections (HadGEM2-ES, NorESM1-M, IPSL-CM5A-LR, GFDL-ESM2M and MIROC-ESM-CHEM) 
Analysis Project, V9, base year 2011, Aguiar et al. 2016). The model is comparatively static and exogenously rescaled to depict possible future scenarios. This means that we do not analyse how pathways develop over time, but compare future snapshots of the economy (e.g. of the year 2050) under different future circumstances (detailed in section 3.2). Based on a consistent set of input-output tables and bilateral trade data, CGE models describe the economy as monetary flows across sectors, agents and regions. These flows are assumed to be in equilibrium with all markets cleared (Shoven and Whalley 1992). The high sectoral resolution enables capturing (inter-)sectoral effects and allows for economic shocks (such as climate change impacts) to be implemented accurately, rather than using coarse damage functions, as it is usually done in integrated assessment models. Another crucial feature of CGE models is the possibility of substitution effects, i.e. economic sectors and agents react to relative price changes by altering their demand patterns and quantities - including the country of origin/destination. This feature sets CGE models apart from multi-regional input-output models as well as network models, which are rather rigid and better suited for short-term analyses. Another key characteristic of CGE models is that factor endowments are scarce and thus constrain overall economic activity (as opposed to e.g. post-Keynesian models which are demand constrained).

The here applied model depicts the world economy as 24 regions, each consisting of 23 sectors and one representative regional household. This regional household is endowed with the production factor labour (differentiated for skilled and unskilled), capital, land and natural resources (including fossil resources), which are supplied to the market and generate factor income (i.e. wages, capital and resource rents). Production factors are assumed to be perfectly mobile across sectors, but immobile across regions. In addition to factor income, the regional household receives tax revenues (based on fixed tax rates). Given the total income, this is either spent for private and public consumption or allocated to savings (investments). Private consumption is specified by a nested constant elasticity of substitution (CES) consumption function, whereas for public consumption, a Leontief consumption function is used. The absolute amount of savings (investment) is determined by a fixed savings rate (i.e. a fixed fraction of income). On the supply side, each of the economic sectors combines factors and intermediate inputs (i.e. outputs from other sectors), again according to sector-specific nested CES production functions. Resource using sectors, such as the oil or gas supply sectors, additionally use natural resources (see Bednar-Friedl et al. (2012) for details on the nesting structures).

Regarding international trade, the model is calibrated to real-world bilateral trade flows under the observed trade policies and costs (implemented as export subsidies, import tariffs, an international transport market and trade margins; as provided by GTAP (Aguiar et al. 2016)). Concerning the flexibility of changing trade partners (import sources), we apply the Armington (1969) assumption: imports and domestically produced goods are imperfect substitutes and can be substituted according to empirically estimated sector-specific elasticities of trade (Hertel et al. 2007). Changes in sectoral trade patterns are thus driven by regional import demand changes, which are triggered by changes in relative international prices (terms of trade). The foreign trade surplus (or deficit) is fixed (fixed trade balance to GDP ratio).

Concerning the regional aggregation, we take a German perspective and consider the importance of trading partners and country-specific climate vulnerability based on Chen et al. (2015) (see Table 1 in SM, section 2). For the sectoral aggregation (Table 2 in SM), we primarily follow the classification of goods and services used by the German Federal Statistical Office and similar considerations as for the regional aggregation. 


\subsection{Scenario framework and baseline calibration}

We distinguish between two types of scenarios: baseline scenarios and climate change scenarios. The baseline scenarios entail the general regional socioeconomic development, but no climatic changes. The climate change scenarios include the same assumptions as the baseline and additionally, climate change-induced labour productivity changes (detailed in section 3.3). By comparing a baseline with a climate change scenario, we isolate the macroeconomic effects that are triggered by climate change.

We incorporate three SSPs (O’Neill et al. 2014; Riahi et al. 2017) to account for uncertainty with respect to different but plausible socioeconomic futures: SSP1, characterised by low challenges for mitigation and adaptation, represents a world on a sustainable pathway with reductions in inequality. SSP2, entailing intermediate challenges for mitigation and adaptation, represents a middle-of-the-road scenario with trends similar to historical patterns. SSP3, involving high challenges for mitigation and adaptation, represents a world in which regional rivalry dominates and environmental issues are neglected. We integrate the quantitative aspects of the SSPs by different assumptions on GDP and population growth rates, land cover, and RCP-SSP specific $\mathrm{CO}_{2}$ prices. ${ }^{3} \mathrm{We}$ therefore use data from IIASA's SSP database (Riahi et al. 2017) on region-specific (i) population growth, driving labour force growth; (ii) crop land cover, driving the growth of land resources; and (iii) GDP growth rates, driving the growth of the capital stock. In addition, we implement an RCP-SSP specific global $\mathrm{CO}_{2}$ tax. ${ }^{4}$ Given these exogenous parameters, we calibrate regional multi-factor productivity improvements as a slack parameter to meet exogenous SSP-specific GDP growth rates. The resulting trade patterns in 2050 reflect Germany's economic characteristics, i.e. there is a trade surplus, and a significant share of both exports and imports is constituted by machinery and electronic equipment, chemical and other industries, construction and service sector (details are given in Fig.2 in the SM, section 3).

\subsection{Implementation of heat-related labour productivity changes}

To implement heat-related labour productivity shocks in the CGE model, we follow a (unit cost) production function approach (Sue Wing and Lanzi 2014). Production activities are modelled as CES production functions, with labour as one of the inputs (expressed as paid wages) that are used to create output. In equilibrium, the value of one unit of output equals the value of all inputs required to produce one unit. To account for climate change-induced productivity losses, we assume that more labour input is necessary per unit of output, i.e. a loss in productivity. This is implemented by multiplying the labour input in the unit cost function by a factor larger than one, calculated as $1-\Delta W A$, as the change in work ability $(\triangle W A)$ is negative. The resulting productivity loss implies that production costs per unit of output (and thus prices) increase, triggering endogenous demand responses and changed output levels in the new equilibrium (as supply equals demand).

\footnotetext{
${ }^{3}$ As pointed out by a reviewer, it would be desirable to capture also differences in trade agreements across the different SSPs. However, the IIASA SSP database does so far only provide region-specific data on GDP, population and land use.

${ }^{4}$ Given by IIASA's SSP-RCP marker scenarios: $3.5 \mathrm{USD} / \mathrm{tCO}_{2}$ for SSP1-RCP4.5, $14 \mathrm{USD} / \mathrm{tCO}_{2}$ for SSP2RCP4.5 and $74 \mathrm{USD} / \mathrm{tCO}_{2}$ for SSP3-RCP4.5 (Fricko et al. 2017). As a positive $\mathrm{CO}_{2}$ price is not compatible with RCP8.5, we assume a $\mathrm{CO}_{2}$ price of zero for all SSPs combined with RCP8.5.
} 


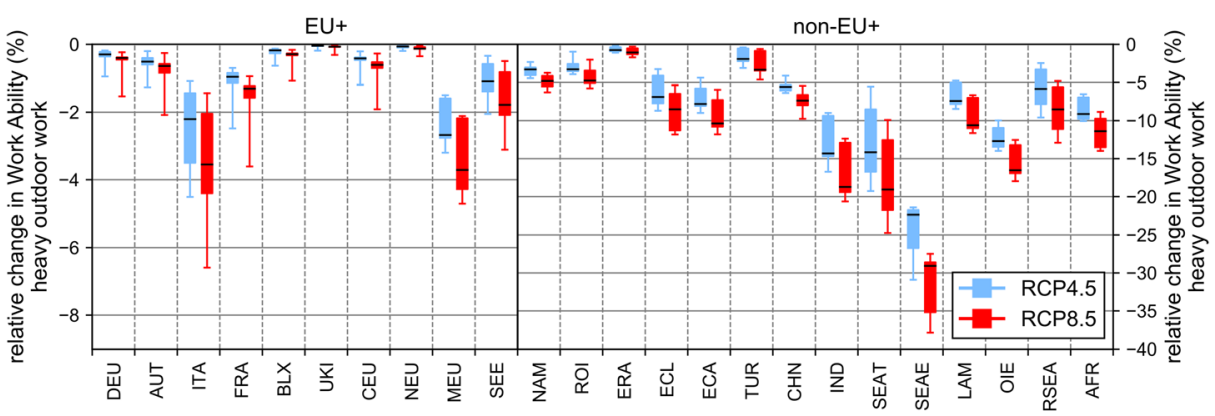

Fig. 2 Boxplots of projected relative changes in heavy outdoor work ability for the EU+ (left) and non-EU+ regions (right) until the mid of the century (Ø2036-2065) for RCP4.5 (blue) and RCP8.5 (red). Boxplots are derived from the five GCM projections (HadGEM2-ES, NorESM1-M, IPSL-CM5A-LR, GFDL-ESM2M and MIROC-ESM-CHEM) under the three SSP scenarios (SSP1, SSP2 and SSP3). The boxes indicate the first and third quartiles, the whiskers extend to the projected minimum and maximum change and the black line indicates the median. See Table 1 in SM for region acronyms

The calculated productivity changes are mapped to the sectors of the CGE model according to work intensities of sectors: We assume service sectors to be light work and to be performed indoors since it consists largely of office work. Work in all manufacturing industries (food, textile, wood, machinery, electronic equipment and transport sectors) is assumed to be medium work and indoor, reflecting work that is mostly physical but does not reach heavy physical work. Finally, agricultural, extraction and the construction sectors are attributed to heavy work and outdoor. A summarising table along with some caveats of sectoral mapping can be found in the SM, section 2.

\section{Results}

\subsection{Heat-related reductions in work ability in 2050 across world regions}

All GCM projections agree on the sign of future WBGT and work ability levels, i.e. a rise in WBGT and accompanying decline in work ability, but there are differences in magnitude. More exhausting work is more strongly affected by rising WBGT compared with less exhausting work. Impacts are in general stronger for RCP8.5 than for RCP4.5, and reductions in outdoor work ability exceed reductions in indoor work abilities for all work intensities at the global level. Therefore, heavy outdoor work ability shows the most sensitive response to rising temperatures. Fig 2 shows boxplots of regional relative changes in work ability for heavy outdoor work until 2036-2065 as projected by the five GCMs for RCP4.5 (in blue) and RCP8.5 (in red). Within Europe (Fig. 2 (left)), reductions are most pronounced for Italy and MEU countries (Cyprus, Greece, Malta, Portugal, Spain), while other countries are only marginally affected. Other world regions (Fig. 2 (right)) are severely impacted such as Southeast Asian countries (SEAT, SEAE and RSEA), India (IND) and oil exporting countries (OIE). On a disaggregated level, the strongest decline in work ability is projected for low-lying equatorial regions, while notable reductions are visible within $\pm 30^{\circ}$ latitude. For single locations in the Amazon region for instance, heavy outdoor work (400W) is projected to decline by more than 50\% under RCP8.5 compared with present levels. Other global hotspots include countries at the Gulf of Guinea, in Central Africa, and in Maritime Southeast Asia (for details see Figs.3 and 4 in SM, section 4). 


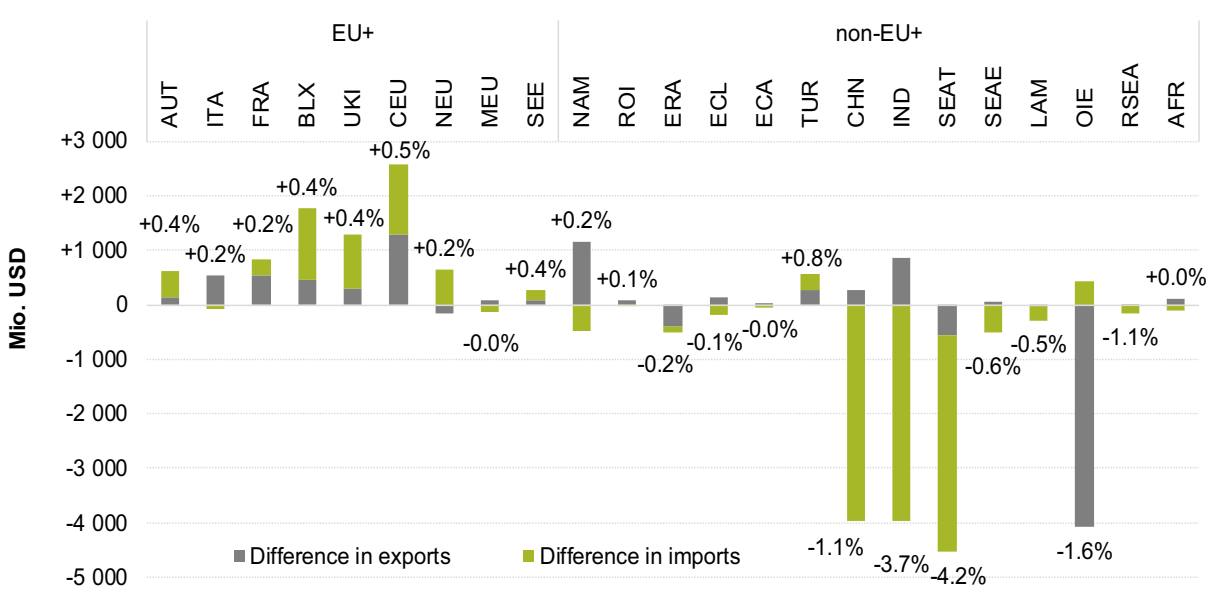

Fig. 3 Absolute change (in USD million, indicated by the bars) of Germany's imports and exports by regions in 2050 due to labour productivity losses as compared with the baseline (SSP2); relative change of external trade balance (in \%) is also indicated; climate projections: HadGEM2-ES for RCP4.5, climatic period 2050 (Ø20362065). See Table 1 in SM for region acronyms

\subsection{Effects of global heat-related labour productivity shocks on Germany}

To explore the altered trade patterns for the German economy caused by regional and sectoral shifts, we focus on RCP4.5 relative to the SSP2 baseline scenario without climate change using the HadGEM2-ES GCM. Results are given for 2050 in relative terms, i.e. in \% deviations from the baseline, or in absolute terms (USD million at 2011 prices).

We find that climate change-induced labour productivity shocks translate into a lower GDP in all regions (Fig.5 in SM, section 5), ranging from $-0.04 \%$ in Turkey (TUR) to $-3.8 \%$ in Southeast Asian textile countries (SEAT; Bangladesh, Thailand, Indonesia, Vietnam, Pakistan and Tunisia). For Germany, GDP is lower by $-0.12 \%$, which is less than the European average impact of $-0.29 \%$. The effect on welfare is stronger ranging between $-0.16 \%$ in Central EU (CEU) and $-7.91 \%$ in India (IND), a country that experiences higher WBGT and where the economy is constituted by labour-intensive sectors. In general, the combination of higher direct climate impacts and a more labour-intensive production in the economy results in negative impacts being stronger on countries outside Europe than on those within Europe for both GDP and welfare.

On aggregate, two effects on Germany's trade flows can be observed: first, total imports decline-imports from outside Europe are reduced and are compensated by up to $38 \%$ by imports from European countries. Second, total exports increase slightly-reductions to non-European countries are overcompensated $(160 \%)$ by increases in exports to EU regions. Especially China $(\mathrm{CHN})$, India, Southeast Asian textile countries and OIE become less attractive trading partners (see Fig.3 ). However, due to comparative advantages, not all trade of Germany with non-EU+ regions is reduced: a slight increase can be observed for Turkey, North America (NAM; including the USA) and Australia, New Zealand, Japan (ROI).

Focussing on the sectoral level, Fig.4 illustrates the shifts of Germany's 10 most important sectors (in value terms in the baseline scenario - indicated by the size of bubbles), differentiated by origin/destination between EU+ regions (horizontal axis) and non-EU+ regions 


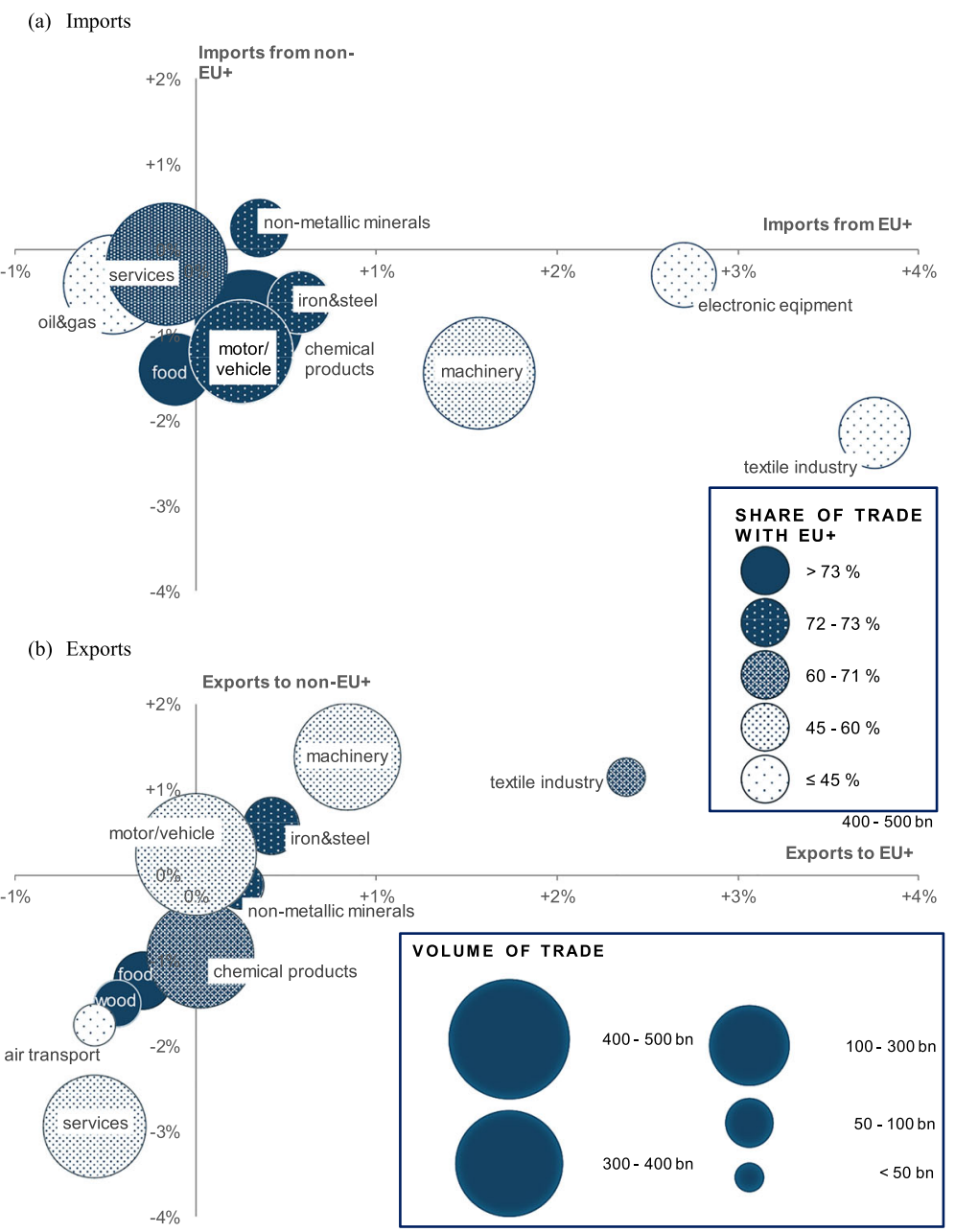

Fig. 4 Relative changes of German imports (a) from and exports (b) to EU+ and non-EU+ regions due to labour productivity losses as compared with the baseline (SSP2) for the 10 largest sectors in the 2050 baseline; climate projections: HadGEM2-ES for RCP4.5. Size of bubble displays the size of the sector in billion USD in the baseline, and shadings displays the share of sectoral trade with EU+ regions. Classes for both represent quintiles of observations. For detailed sector description, see Table 2 in SM

(vertical axis). The shading represents the trade intensity with EU+ regions (a darker shading indicating a higher share of trade with European regions). These sectors cover $82 \%$ of total German imports and $90 \%$ of total German exports, respectively.

Fig 4a shows the shift of imports from outside Europe to within Europe as sectoral production in non-EU+ regions loses competitiveness. This relocation effect is most strongly visible for the labour-intensive textile industry, for machinery (incl. data processing equipment, electronic and optical products) and electronic equipment. For these sectors, the share that is imported from outside Europe is larger than for other sectors already in the baseline. The same impact but smaller in size can be observed for motor and motor vehicles (incl. transport equipment), chemical products (incl. rubber and plastic products) and iron and steel products, where imports in the baseline are mainly coming from EU+ regions. 


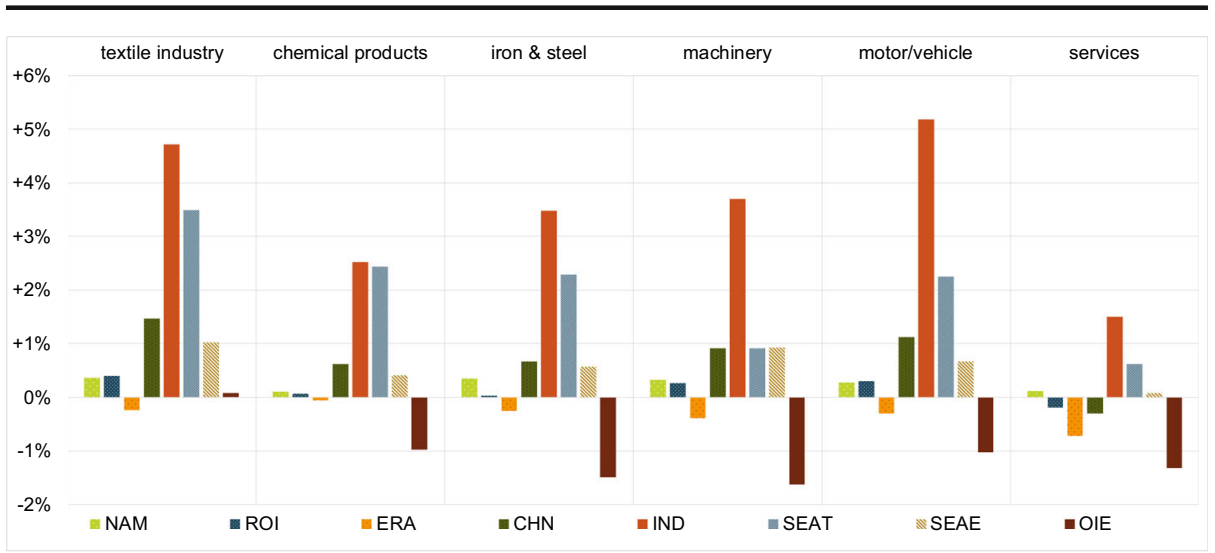

Fig. 5 Change in Germany's competitiveness (change in ratio of foreign to domestic price level) for relevant sectors and regions due to labour productivity losses as compared with the baseline (SSP2); climate projections: HadGEM2-ES for RCP4.5, climatic period 2050 (Ø2036-2065). See Table 1 in SM for region acronyms

For exports, we find a different pattern (Fig.4b): sectoral changes are distributed across the first and the third quadrant, implying that heat-related productivity losses lead to either higher or lower exports to both EU+ and non-EU+ regions. With increasing wage rates, capital becomes relatively cheaper as labour is the limiting factor of production. Thus, national production focuses on the production of goods that uses the cheaper factor intensively and also, exports adjust to that. As a consequence, higher exports emerge for mostly capitalintensive sectors such as machinery and iron and steel but also for sectors with a competitive advantage such as the textile industry to both European and non-European countries. Exports to all regions are lower in sectors that use labour, the relatively more expensive factor, more intensively such as services, wood and food products, but also air transport. Exports of the chemical industry (CRP) are mainly lower to non-EU+ regions as the loss of competitiveness decreases demand in sales markets.

As the driving force of changes in trade patterns, Fig.5 shows how Germany's competitiveness, measured by the ratio of foreign to domestic production prices, change for important trading partners and sectors. Patterns clearly show that Germany's competitiveness improves relative to large trading partners outside Europe such as China, India and Southeast Asian countries (SEAT and SEAE). A comparative advantage among non-EU+ regions can be detected for ROI, where relative price effects are small and thus trade relations slightly increase (cf. Fig.3 ). In most sectors, among non-EU+ regions, Eurasian countries (ERA) improve their competitiveness, which is reflected in a smaller decrease in German trade relations with this region as compared with other non-EU+ regions. Prices in OIE (including Russia) decrease due to reduced global demand for energy goods in the climate change scenario. Consequently, available income decreases in these countries, which is reflected by the large decrease of German exports to OIE countries (cf. Fig 3 For machinery and motor/vehicle, Germany realises a competitive advantage because production costs are higher in non-EU+ regions; therefore, less of these products is imported to Germany and more is produced domestically and exported (cf. Fig.4 ). For the service sector, one needs to consider that climate change affects GDP in all regions and thus aggregate demand decreases. Also, service sectors are assumed to be light indoor work, which experience the lowest impact. Consequently, the activity level in almost all regions decreases and both imports and exports decrease. 


\subsection{Robustness across climate and socioeconomic scenarios and different global climate models}

As a robustness check, we compare key results across all GCM-RCP-SSP combinations. Fig 6 shows how changes in labour productivity affect imports and exports as well as Germany's GDP and welfare ${ }^{5}$ across three socioeconomic and two emission scenarios. Fig 6 displays all model runs in a box plot for (a) RCP4.5 (blue) and RCP8.5 (red) and (b) SSP1 (orange), SSP2 (green) and SSP3 (purple). The results are again given for 2050 in relative terms, which indicate a $\%$ deviation from the baseline scenario without climate change.

The direction of effects on Germany's trade, GDP and welfare are robust across emission and socioeconomic scenarios and climate models. Both imports from and exports to EU+ regions are higher in a world with climate change, and the opposite is true for non-EU+ regions - imports from and exports to non-EU+ regions are lower. The range across SSPs and GCMs (Fig.6a) in the lower emission scenario RCP4.5 (higher emission scenario RCP8.5) lies between +0.27 and $+0.49 \%(+0.39 \%$ and $+0.7 \%)$ for imports from EU+ regions and between +0.15 and $+0.31 \%(+0.22 \%$ and $+0.43 \%)$ for exports to EU+ regions. The negative effects on imports from and exports to non-EU+ regions for RCP4.5 (RCP8.5) lie between 0.89 and $-1.71 \%(-1.27 \%$ and $-2.46 \%)$ and between -0.07 and $-0.33 \%(-0.1 \%$ and $0.5 \%)$, respectively. Compared with variations across RCPs, differences between SSPs are much smaller and insignificant (Fig.6b), which is also visible by the wide ranges stemming from differences in emission scenarios. There is a significant difference in the shift of exports, where in SSP3 (regional rivalry), exports to EU+ regions increase more and exports to nonEU+ regions decline less than in SSP2 (middle of the road) and SSP1 (sustainability).

Although the German trade surplus increases in all model runs, the effects on German GDP and welfare are clearly negative (for Germany but also every other European country). Hence, the exploitation of comparative advantages cannot prevent welfare losses. In RCP4.5 (RCP8.5), the reduction in domestic GDP ranges between -0.05 and $-0.29 \%(-0.06 \%$ and $-0.41 \%$ ) while the reduction in welfare is slightly more pronounced with a range of -0.11 to $-0.31 \%(-0.17 \%$ and $-0.46 \%$ ) (Fig.6a). In general, the effects are stronger with a higher emission scenario (RCP8.5 as compared with RCP4.5) and higher challenges for mitigation and adaptation (SSP3 compared with SSP2 and SSP1). Additionally, the direction of the results does not change across GCMs, thus results are robust with respect to climate modelling. The effects on total trade flows, as well as on GDP and welfare, might seem small in size, but results on sectoral and regional trade flows are much larger (see section 4.2).

To disentangle how strongly effects outside Europe drive the direction and magnitude of the effects to Germany's trade balance, we also run a scenario, where we assume that climate change would occur only outside Europe but would leave European countries unharmed. We find that there are no substantial changes in the results with $-0.11 \%$ for GDP and $-0.16 \%$ for welfare in Germany. This is also mainly driven by the fact that the direct climate impact is relatively small in Europe with reductions of work ability of around 1\%. Despite Germany having (currently) its main trading partners within Europe, its economy would still be strongly affected by spill-over effects triggered by climate change-induced labour productivity shocks occurring outside Europe. There are three key factors that drive this result. First, due to regional differences in the magnitude of climate change, labour productivity losses are found to be stronger outside Europe, particularly in Southeast Asia and the Middle East. Second,

\footnotetext{
${ }^{5}$ Welfare is measured as the Hicks'ian equivalent variation of income.
} 
(a) Variation between emission scenarios (RCPs)

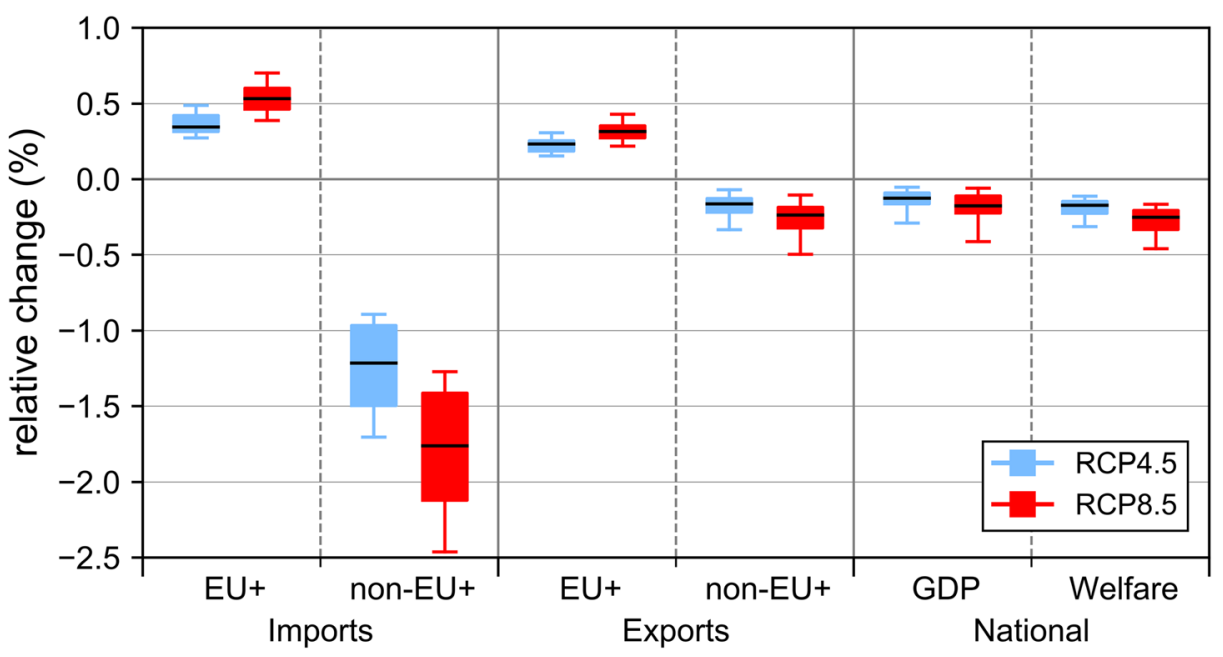

(b) Variation between socioeconomic development (SSPs)

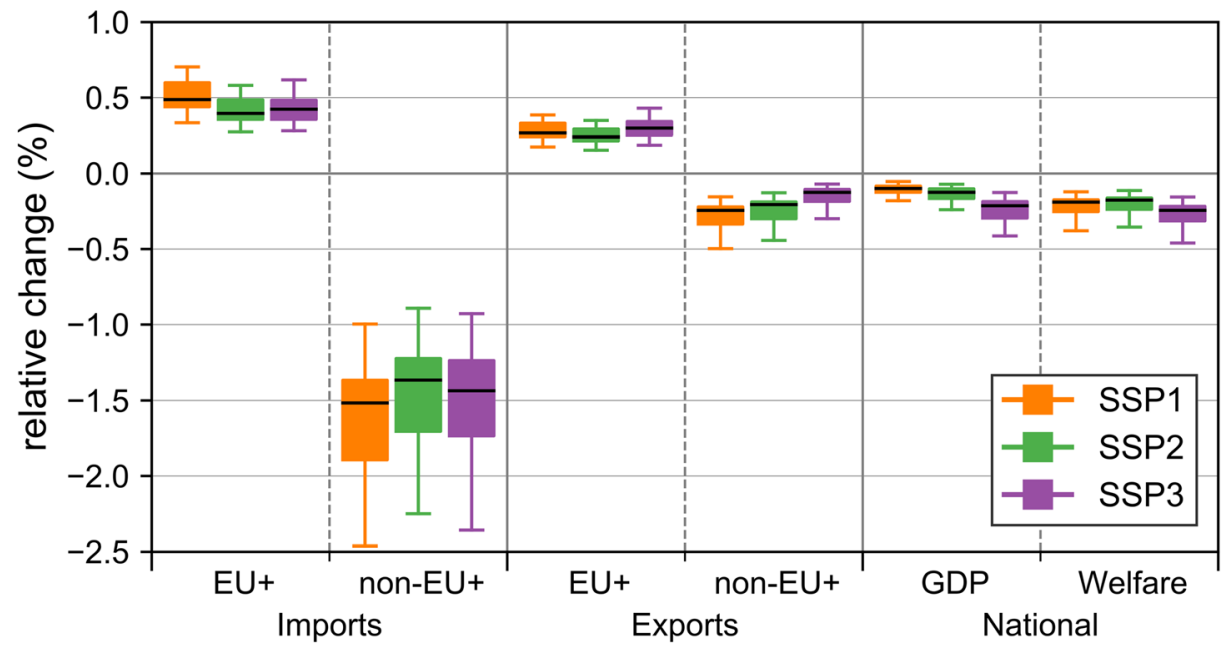

Fig. 6 Relative change in German imports, exports, GDP and welfare in 2050 due to labour productivity losses for climatic period 2050 (Ø2036-2065) relative to the baseline for a variation between emissions scenarios (RCPs) and $\mathbf{b}$ variation between socioeconomic development (SSPs). Boxplots are derived from the combination of a five GCM projections (HadGEM2-ES, NorESM1-M, IPSL-CM5A-LR, GFDL-ESM2M and MIROC-ESMCHEM) and three SSP scenarios (SSP1, SSP2 and SSP3) and b five GCMs and two emission scenarios (RCP4.5, RCP8.5); the boxes indicate the first and third quartiles, the whiskers extend to the projected minimum and maximum changes, and the black line indicates the median

some of Germany's key trading partners outside Europe, namely China and India, are strongly affected by heat-related productivity losses due to climate change. Third, countries differ in their sectoral contribution to GDP, and therefore, in how large the share of high intensity work is in the overall economy and how labour-intensive or extensive the production processes are. Since Germany imports commodities that are produced in labour-intensive sectors outside Europe, the negative impact on Germany's imports from these countries is stronger, and due to 
reduced disposable income, also, the effect on exports to these countries is stronger than on European trade flows.

Finally, to test the robustness of results regarding modelling assumptions, we performed multiple sensitivity analyses. Results are detailed in SM section 6, we give a brief overview here. First, the assumptions on how sectors are mapped to labour intensity and how susceptible they are to temperature changes are tested. Results for Germany show that impacts are decreasing compared with the central run when indoor activities remain completely unaffected and only outdoor labour loses productivity, however, variations in GDP and welfare effects are small. Impacts on trade flows become much smaller both for exports and imports, and the same is true for national GDP for all other model regions.

Second, we vary the substitution elasticities between capital and labour in the production function. This leaves the impact shock unchanged but varies the substitutability of capital for labour when labour becomes less productive and thus more expensive. An easy substitution of the two input factors indicates less severe impacts from a shock as substitution is not costly, while a rigid system implies higher losses from a shock. We find that GDP effects for Germany turn positive once the production becomes very rigid as the competitive advantage for Germany (and generally for European regions) becomes stronger when labour is harder to substitute by capital, and the direct physical impacts are strongest in regions outside Europe. For German welfare though, qualitative results remain unchanged across all alterations. NonEU+ regions would experience lower damages on GDP, if the elasticities of substitution between capital and labour were very high and thus easy to substitute away from the increasingly costly input factor (labour).

Third, through the modification of the subregional elasticities, the ease of exchanging imports of one region for imports of another region is examined, thus allowing trade relations to be more or less flexible as compared with the central run. Again, a flexible system is assumed to be more resilient to shocks and thus be less harmed; however, this also depends on the initial situation of a country. Once imports become very flexible, German GDP turns positive as Germany can switch imports smoothly. This is also reflected in the variation of imports and exports: when only the price decides on import source or export destination, the observed shift from non-EU+ to EU+ regions becomes even stronger. In a scenario with very low elasticities of substitution, negative effects on German GDP and welfare are largest as the combination of a change in relative prices and the restriction on trade reactions implies adverse consequences. While the magnitude of the effects of GDP and welfare change across sensitivity analyses, the direction of the effects remains unaffected.

Overall, we find that all results for welfare are robust, regarding the direction of the effect, across all alterations. GDP effects for Germany, however, turn positive once capital is hardly substitutable for labour in the production process or when imports can easily be sourced from anywhere.

\section{Discussion and conclusion}

In this paper we demonstrate that the spill-over effects of global heat-related labour productivity losses to Germany's trade flows are significant by 2050 . While the intensity of Germany's trade with other European countries might suggest that spill-over effects from these regions are in the same order of magnitude as spill-over effects from outside Europe, we find on the contrary that almost the total effect on Germany's trade balance is 
caused by labour productivity losses outside Europe. In particular, compared with a 2050 baseline without climate change, imports from outside Europe decrease by up to $-2.46 \%$ (relative to baseline imports from European countries). Imports from other European regions increase by up to $+0.70 \%$ (relative to baseline imports from non-European countries), leading to a decline of total imports by up to $-0.83 \%$ (relative to total baseline imports). Total exports from Germany increase by up to $+0.16 \%$, as exports to other European regions increase by up to $+0.43 \%$, while exports to regions outside Europe decline due to decreased demand by up to $-0.50 \%$.

In terms of sectors, we find that total imports in absolute values decline strongest for textiles and wearing apparel, machinery, crude oil and gas, construction, and motor vehicles. In contrast, imports increase (to lower extent) in manufacturing of non-metallic mineral products, precious and non-ferrous metals, service sectors, and wood and paper products as well as manufacturing of basic iron and steel and fabricated metal products. Germany's exports are significantly lower in services and the chemical industry in a climate change scenario. Lower exports are also observed for air transport, food, beverages and tobacco, and refined oil products. However, because of comparative advantages, some German trade sectors see substantially higher exports in a climate change scenario, such as machinery and data processing equipment, the construction sector, the textile industry and agricultural sectors.

While an increase in the German trade surplus could be viewed as beneficial from a German perspective at first glance, it is important to consider that both German GDP and welfare decline in all central model runs and that the effect on welfare is slightly stronger than on GDP (up to $-0.46 \%$ and $-0.41 \%$, respectively). Hence, our results show that the German economy is relatively better off than other world regions because it is less affected by direct impacts and can partly compensate losses in trade with regions outside Europe by gains in trade with European regions. Put differently, all regions loose in terms of GDP and welfare compared with the baseline scenarios without climate change, and therefore, higher trade within Europe only displays a comparative improvement for Germany, but not an absolute one.

Regarding robustness of results to different emission and socioeconomic scenarios, we find that a higher emission scenario (RCP8.5 instead of RCP4.5) intensifies the effects. With respect to socioeconomic developments, impacts tend to be higher when challenges for mitigation and adaptation are higher (SSP3 as compared with SSP2 and even more so compared with SSP1); however, differences are small. Using climate projections from five different GCMs does not affect the direction of results.

While the present paper focused on the impacts of heat stress on labour productivity, there are several adaptation options available and necessary that can counteract health impacts and productivity losses (Smith et al. 2014). Options include higher shares of air-conditioning (addressed by Takakura et al. (2017)), a shift of working hours to cooler periods of the day (Day et al. 2019) or the opportunity to adjust clothing (Morgan and de Dear 2003), but also changes in the ability of people to cope with heat stress (Kjellstrom et al. 2016). Moreover, trade could ameliorate the effects of climate change (Schenker and Stephan 2012), particularly when a country maintains a balanced trade balance with main trading partners (Willner et al. 2018). The role of trade becomes also visible when comparing our results under SSP3 (regional rivalry) to SSP1 (sustainability) and SSP2 (middle of the road). We find that negative effects on German GDP in SSP1 are approximately half of the effect in SSP3. However, there might be also physical restrictions to trade, e.g. when shipping is impaired due to sea level rise (Chatzivasileiadis et al. 2016). 
Finally, several limitations need to be considered in the present paper, which should be addressed by future research. We have implemented the common assumption that the ratio of the trade balance to GDP remains constant in the baseline specification (as in the base year). As SSP storylines also refer to the rivalry among economies, it would be interesting to elaborate quantifiable trade narratives that translate (e.g.) into SSP-specific trade tariffs and trade balances. Further, technological progress and in particular digitalisation are likely to affect work by mid of the century. While technological change is partly captured by (exogenous) productivity changes, digitalisation and innovations changing work patterns in the future are not included. With respect to the scope of the present study, we aimed at demonstrating the importance of the transferability of impacts and thus only analysed the effects that arise from heat-related labour productivity losses, while other climate change impacts (e.g. sea level rise, riverine flooding) could lead to different results. Furthermore, we estimated future WBGT values by a simple relationship based on daily mean temperature and humidity values and hence did not account for particular times during a day when work might be performed. Also, possible increases in labour productivity are excluded; however, some trading partners like Russia may benefit from higher temperatures in reality. In any case, the qualitative insights from this paper and resulting implications are likely to remain valid even when altering or refining assumptions.

Acknowledgements Open access funding provided by University of Graz. We thank participants of the AURÖ Workshop 2018 and the EAERE-FEEM-VIU Summer School 2018 for discussion and helpful comments on earlier versions of the manuscript. We also acknowledge the World Climate Research Programme's Working Group on Coupled Modelling and all participating climate modelling groups for producing and making available their model output, as well as the ISIMIP team for providing bias-corrected CMIP5 data.

Funding information NK and GB gratefully acknowledge financial support from the German Federal Environment Agency under research grant FKZ 3716481020 (Impact CHAIN). MJ acknowledges funding from the Austrian Climate and Energy Fund under its 10th call of the Austrian Climate Research Programme, project COIN-INT (project number B6770197).

Open Access This article is licensed under a Creative Commons Attribution 4.0 International License, which permits use, sharing, adaptation, distribution and reproduction in any medium or format, as long as you give appropriate credit to the original author(s) and the source, provide a link to the Creative Commons licence, and indicate if changes were made. The images or other third party material in this article are included in the article's Creative Commons licence, unless indicated otherwise in a credit line to the material. If material is not included in the article's Creative Commons licence and your intended use is not permitted by statutory regulation or exceeds the permitted use, you will need to obtain permission directly from the copyright holder. To view a copy of this licence, visit http://creativecommons.org/licenses/by/4.0/.

\section{References}

Aaheim A, Amundsen H, Dokken T, Wei T (2012) Impacts and adaptation to climate change in European economies. Glob Environ Chang 22:959-968

Aguiar A, Narayanan B, McDougall R (2016) An overview of the GTAP 9 data base. J Glob Econ Anal 1:181208

Armington PS (1969) A theory of demand for products distinguished by place of production (Une theorie de la demande de produits differencies d'apres leur origine) (Una teoria de la demanda de productos distinguiendolos segun el lugar de produccion). Staff Pap - Int Monet Fund 16:159. https://doi. org/10.2307/3866403

Bednar-Friedl B, Schinko T, Steininger KW (2012) The relevance of process emissions for carbon leakage: a comparison of unilateral climate policy options with and without border carbon adjustment. Energy Econ 34(Supplement 2):S168-S180. https://doi.org/10.1016/j.eneco.2012.08.038 
Benzie M, Hedlund J, Carlsen H (2016) Introducing the transnational climate impacts index: indicators of country-level exposure-methodology report. Stockholm Environment Institute, Stockholm

Bröde P, Fiala D, Lemke B, Kjellstrom T (2017) Estimated work ability in warm outdoor environments depends on the chosen heat stress assessment metric. Int J Biometeorol. https://doi.org/10.1007/s00484-017-1346-9

Burke M, Hsiang SM, Miguel E (2015) Global non-linear effect of temperature on economic production. Nature 527:235-239. https://doi.org/10.1038/nature15725

Challinor A, Adger WN, Di Mauro M et al (2016) UK climate change risk assessment evidence report: chapter 7. International Dimensions, London

Chatzivasileiadis TN, Hofkes MW, Kuik OJ, Tol RSJ (2016) Full economic impacts of sea level rise: loss of productive resources and transport disruptions. Univ Sussex Working Paper Series

Chen C, Noble I, Hellmann J et al (2015) Country index technical report. University of Notre Dame

Ciscar J, Feyen L, Soria A, et al (2014) Climate impacts in Europe. Results from the JRC PESETA II Project

Ciscar J-C, Iglesias A, Feyen L et al (2011) Physical and economic consequences of climate change in Europe. Proc Natl Acad Sci U S A 108:2678-2683

DARA, Climate Vulnerable Forum (2012) Climate vulnerability monitor: a guide to the cold calculus of a hot planet. DARA, Madrid

Day E, Fankhauser S, Kingsmill N et al (2019) Upholding labour productivity under climate change: an assessment of adaptation options. Clim Pol 19:367-385. https://doi.org/10.1080 /14693062.2018.1517640

Dellink R, Lanzi E, Chateau J (2017) The sectoral and regional economic consequences of climate change to 2060. Environ Resour Econ. https://doi.org/10.1007/s10640-017-0197-5

Destatis (2019) Globalisation indicators. https://www.destatis.de/EN/Themes/Economy/GlobalisationIndicators/Tables/01_02_03_44_VGR.html

Dunne JP, Stouffer RJ, John JG (2013) Reductions in labour capacity from heat stress under climate warming. Nat Clim Chang. https://doi.org/10.1038/nclimate1827

Eskeland GS, Mideksa TK (2010) Electricity demand in a changing climate. Mitig Adapt Strateg Glob Chang 15: 877-897. https://doi.org/10.1007/s11027-010-9246-x

European Environment Agency (2017) Climate change, impacts and vulnerability in Europe 2016: an indicatorbased report

Fricko O, Havlik P, Rogelj J et al (2017) The marker quantification of the shared socioeconomic pathway 2: a middle-of-the-road scenario for the 21st century. Glob Environ Chang 42:251-267. https://doi.org/10.1016/j. gloenvcha.2016.06.004

Golombek R, Kittelsen SAC, Haddeland I (2012) Climate change: impacts on electricity markets in Western Europe. Clim Chang 113:357-370. https://doi.org/10.1007/s10584-011-0348-6

Grundstein A, Cooper E (2018) Assessment of the Australian Bureau of Meteorology wet bulb globe temperature model using weather station data. Int J Biometeorol 62:2205-2213. https://doi.org/10.1007/s00484-0181624-1

Hedlund J, Fick S, Carlsen H, Benzie M (2018) Quantifying transnational climate impact exposure: new perspectives on the global distribution of climate risk. Glob Environ Chang 52:75-85. https://doi. org/10.1016/j.gloenvcha.2018.04.006

Hempel S, Frieler K, Warszawski L et al (2013) A trend-preserving bias correction - the ISI-MIP approach. Earth Syst Dyn 4:219-236. https://doi.org/10.5194/esd-4-219-2013

Hertel T, Hummels D, Ivanic M, Keeney R (2007) How confident can we be of CGE-based assessments of free trade agreements? Econ Model 24:611-635. https://doi.org/10.1016/j.econmod.2006.12.002

Hewitson B, Janetos AC, Carter TR, et al (2014) Regional Context. In: Climate Change 2014: Impacts, Adaptation, and Vulnerability

INFRAS, Ecologic, Rütter (2007) Auswirkungen der Klimaänderung auf die schweizer Volkswirtschaft (Internationale Einflüsse). Zürich/Berlin/Rüschlikon

Kankaanpää S, Carter TR (2007) Implications of international climate change impacts for Finland. Finnish Environment Institute (SYKE), Helsinki

Kjellstrom T (2016) Impact of climate conditions on occupational health and related economic losses: a new feature of global and urban health in the context of climate change. Asia Pac J Public Health 28: $28 \mathrm{~S}-37 \mathrm{~S}$

Kjellstrom T, Holmer I, Lemke B (2009a) Workplace heat stress, health and productivity-an increasing challenge for low and middle-income countries during climate change. Glob Health Action 2:2047. https://oi. org/10.3402/gha.v2i0.2047

Kjellstrom T, Kovats RS, Lloyd SJ et al (2009b) The direct impact of climate change on regional labor productivity. Arch Environ Occup Health 64:217-227. https://doi.org/10.1080/19338240903352776

Kjellstrom T, McMichael AJ (2013) Climate change threats to population health and well-being: the imperative of protective solutions that will last. Glob Health Action 6:20816. https://doi.org/10.3402/gha.v6i0.20816 
Liljegren JC, Carhart RA, Lawday P et al (2008) Modeling the wet bulb globe temperature using standard meteorological measurements. J Occup Environ Hyg 5:645-655. https://doi.org/10.1080 $/ 15459620802310770$

Liverman D (2016) U.S. national climate assessment gaps and research needs: overview, the economy and the international context. Clim Chang 135:173-186. https://doi.org/10.1007/s10584-015-1464-5

Lühr O, Kramer DJ-P, Lambert J et al (2014) Analyse spezifischer Risiken des Klimawandels und Erarbeitung von Handlungsempfehlungen für exponierte industrielle Produktion in Deutschland (KLIMACHECK). Prognos / adelphi, Berlin

Morgan C, de Dear R (2003) Weather, clothing and thermal adaptation to indoor climate. Clim Res 24:267-284. https://doi.org/10.3354/cr024267

Moss RH, Edmonds JA, Hibbard KA et al (2010) The next generation of scenarios for climate change research and assessment. Nature 463:747-756. https://doi.org/10.1038/nature08823

Nicholls RJ, Kebede AS (2012) Indirect impacts of coastal climate change and sea-level rise: the UK example. Clim Pol 12:S28-S52. https://doi.org/10.1080/14693062.2012.728792

NIOSH (1986) Occupational exposure to hot environments: revised guidelines for worker safety. National Institute for Occupational Safety and Health

O'Neill BC, Kriegler E, Riahi K et al (2014) A new scenario framework for climate change research: the concept of shared socioeconomic pathways. Clim Chang 122:387-400. https://doi.org/10.1007/s10584-013-0905-2

Oppenheimer M, Campos M, Warren R et al (2014) Emergent risks and key vulnerabilities. In: Climate Change 2014: Impacts. Adaptation, and Vulnerability

Parsons K (2014) Human thermal environments: the effects of hot, moderate, and cold environments on human health, comfort, and performance. CRC press

PricewaterhouseCoopers (PwC) (2013) International threats and opportunities of climate change for the UK. http://www.pwc.co.uk/services/sustainability-climate-change/insights/international-threats-andopportunities-of-climate-change-to-the-uk.html

Riahi K, van Vuuren DP, Kriegler E et al (2017) The shared socioeconomic pathways and their energy, land use, and greenhouse gas emissions implications: an overview. Glob Environ Chang 42:153-168. https://doi. org/10.1016/j.gloenvcha.2016.05.009

Roson R, Sartori M (2016) Estimation of climate change damage functions for 140 regions in the GTAP 9 database. J Glob Econ Anal 1:78-115

Roson R, Van der Mensbrugghe D (2012) Climate change and economic growth: impacts and interactions. Int J Sustain Econ 4:270-285

Roudier P, Andersson JCM, Donnelly C et al (2016) Projections of future floods and hydrological droughts in Europe under $\mathrm{a}+2^{\circ} \mathrm{C}$ global warming. Clim Chang 135:341-355. https://doi.org/10.1007/s10584-015-15704

Schenker O (2013) Exchanging goods and damages: the role of trade on the distribution of climate change costs. Environ Resour Econ 54:261-282. https://doi.org/10.1007/s10640-012-9593-Z

Schenker O, Stephan G (2012) Terms-of-trade and the funding of adaptation to climate change and variability: an empirical analysis. SSRN Electron J. https://doi.org/10.2139/ssrn.2141958

Shoven JB, Whalley J (1992) Applying general equilibrium. Cambridge University Press, Cambridge, United Kingdom

Smith KR, Woodward A, Campbell-Lendrum D, et al (2014) Human health: impacts, adaptation, and co-benefits. In: Climate Change 2014: Impacts, Adaptation, and Vulnerability. Part A: Global and Sectoral Aspects. Contribution of Working Group II to the Fifth Assessment Report of the Intergovernmental Panel on Climate Change. Cambridge University Press, Cambridge, United Kingdom and New York, NY, USA, pp 709-754

Steininger KW, König M, Bednar-Friedl B et al (eds) (2015) Economic evaluation of climate change impacts. Springer International Publishing, Cham

Sue Wing I, Lanzi E (2014) Integrated assessment of climate change impacts. OECD Environ Work Pap No:66. https://doi.org/10.1787/5jz2qcjsrvzX-en

Takakura J, Fujimori S, Takahashi K et al (2017) Cost of preventing workplace heat-related illness through worker breaks and the benefit of climate-change mitigation. Environ Res Lett 12:064010. https://oi. org/10.1088/1748-9326/aa72cc

Taylor KE, Stouffer RJ, Meehl GA (2012) An overview of CMIP5 and the experiment design. Bull Am Meteorol Soc 93:485-498. https://doi.org/10.1175/BAMS-D-11-00094.1

Foresight UK (2011) International dimensions of climate change. UK Government Office for Science, London

Vonk M, Bouwman A, van Dorland R, Eerens H (2015) Worldwide climate effects: risks and opportunities for the Netherlands. PBL Netherlands Environmental Assessment Agency, The Hague

Wachsmuth J, Blohm A, Gößling-Reisemann S et al (2013) How will renewable power generation be affected by climate change? The case of a metropolitan region in northwest Germany. Energy 58:192-201. https://oi. org/10.1016/j.energy.2013.06.035 
Warszawski L, Frieler K, Huber V et al (2014) The inter-Sectoral impact model intercomparison project (ISIMIP): project framework. Proc Natl Acad Sci 111:3228-3232. https://doi.org/10.1073/pnas.1312330110

Watkiss P, Hunt A (2012) Projection of economic impacts of climate change in sectors of Europe based on bottom up analysis: human health. Clim Chang 112:101-126. https://doi.org/10.1007/s10584-011-0342-z

Wenz L, Levermann A (2016) Enhanced economic connectivity to foster heat stress-related losses. Sci Adv 2: e1501026-e1501026. https://doi.org/10.1126/sciadv.1501026

West C, Croft S, Dawkins E, et al (2015) Identifying and exploring key commodity chains at risk from climate impacts. In: AVOID2. WPF3: The impact of weather extremes on agricultural commodity prices

Willner SN, Otto C, Levermann A (2018) Global economic response to river floods. Nat Clim Chang 8:594-598. https://doi.org/10.1038/s41558-018-0173-2

Zander KK, Botzen WJW, Oppermann E et al (2015) Heat stress causes substantial labour productivity loss in Australia. Nat Clim Chang 5:647-651. https://doi.org/10.1038/nclimate2623

Publisher's note Springer Nature remains neutral with regard to jurisdictional claims in published maps and institutional affiliations.

\section{Affiliations}

\section{Nina Knittel ${ }^{1} \cdot$ Martin W. Jury $^{1} \cdot$ Birgit Bednar-Friedl $^{1,2} \cdot$ Gabriel Bachner $^{1} \cdot$ Andrea K. $^{2}$ Steiner ${ }^{1,3}$}

1 Wegener Center for Climate and Global Change, University of Graz, Brandhofgasse 5, 8010 Graz, Austria

2 Institute of economics, University of Graz, Graz, Austria

3 Institute for Geophysics, Astrophysics, and Meteorology/Institute of Physics, University of Graz, Graz, Austria 